Effusiella, Elongatia, Lalexia, Mystacorchis, Niphanta, Physosiphon, Physothallis, Rhynchopera, Salpistele, Talpinaria, and Unciferia). Based on analyses that have evaluated the phylogenetic relationships of Stelis, in this work we compare and discuss both proposals. The concept of Stelis s.1. encompasses a monophyletic group with variable morphology among its members but with strong support. Against this, it has been argued that there are no morphological synapomorphies that define the group and, hence, it is preferable to divide it. However, this consideration forgets the fact that morphology is not the only criterion useful in delimiting a taxonomic group. On the other hand, following this approach leads to taxonomic inflation and complicates a classification system that otherwise would be easier to learn and use. Some groups segregated from Stelis s.l. are not monophyletic (Dracontia, Effusiella); others are monotypic and defined by autapomorphies (Lalexia, Mystacorchis). Furthermore, more phylogenetic work is necessary to evaluate the position of some species previously transferred to Stelis s.1. that seem to be more closely related to Pleurothallis (e.g. Stelis quadrifida, S. restrepioides).

\title{
A newly recognized clade of Pleurothallis with Mesoamerican distribution
}

\author{
M. Wilson ${ }^{1 *}$, F. Pupulin², F. L. Archila-Morales ${ }^{3}$, A. Damon ${ }^{4} \&$ R. Solano-Gomez ${ }^{5}$ \\ ${ }^{1 *}$ Biology Department, The Colorado College, Colorado Springs, CO 80903, USA; ${ }^{2}$ Jardin Botanico Lankester, \\ Universidad de Costa Rica, Cartago, Costa Rica; ${ }^{3}$ Estación Experimental de Orquídeas de Guatemala, Cobán, \\ Guatemala; ${ }^{4} \mathrm{El}$ Colegio de la Frontera Sur (ECOSUR), Tapachula, Chiapas, Mexico; ${ }^{5}$ Instituto Politécnico \\ Nacional, Centro Interdisciplinario de Investigación para el Desarrollo Integral Regional unidad Oaxaca, Santa \\ Cruz Xoxocotlan, Oaxaca, Mexico \\ *Author for correspondence: mwilson@coloradocollege.edu
}

Phylogenetic studies of Pleurothallis sensu lato have revealed a previously unrecognized clade of Pleurothallis species, including to date: Pleurothallis aurita, P. bitumida, P. bogarinii, P. cobriformis, $P$. dorotheae, P. excavata, P. nitida, P. saccatilabia, P. sanchoi, $P$. scaphipetala, P. simulans, and two as yet undescribed species. These species were previously considered part of Pleurothallis subgenus Pleurothallis section Macrophyllae-Fasciculatae, but this section was segregated from Pleurothallis by Luer and along with $P$. section Pleurothallis subsection Acroniae was raised to generic level as Acronia. In an alternate interpretation by Szlachetko et al., P. section Macrophyllae-Fasciculatae was alone segregated from Pleurothallis as genus Zosterophyllanthos. The aforementioned species, with the exception of $P$. bogarinii, are listed under these alternate genera in the World Checklist of
Selected Plant Families, but the names are considered synonyms of Pleurothallis. Samples of these species were obtained from collections in Costa Rica, Guatemala, Mexico, Panama, and the U.S. Analyses of nuclear ITS and plastid rpoB and matK sequences for these species reveal a well-supported clade which can be interpreted as either sister to or part of the Pleurothallis sensu stricto clade but which is distinct both from the clade containing the other species of P. section Macrophyllae-Fasciculatae and from the clades containing species of $P$. section Pleurothallis subsection Acroniae. These phylogenetic data, differences in floral and foliar morphology from other species in $P$. section Macrophyllae-Fasciculatae; and, as far as we know, an exclusively Mesoamerican distribution (Costa Rica, Guatemala, Mexico, and Panama), strongly indicate that a new subgenus of Pleurothallis is warranted for the clade. 